\title{
Health leadership education programs, best practices, and impact on learners' knowledge, skills, attitudes, and behaviors and system change: a literature review
}

\author{
This article was published in the following Dove Press journal: \\ Journal of Healthcare Leadership \\ 12 May 2014 \\ Number of times this article has been viewed
}

\author{
Emmanuelle Careau' \\ Gjin Biba' \\ Rosemary Brander ${ }^{2}$ \\ Janice P Van Dijk ${ }^{2}$ \\ Sarita Verma ${ }^{3}$ \\ Margo Paterson ${ }^{2}$ \\ Maria Tassone ${ }^{3}$ \\ 'Center for Interdisciplinary \\ Research in Rehabilitation and Social \\ Integration, Université Laval, Québec, \\ QC, ${ }^{2}$ Office of Interprofessional \\ Education and Practice, Queen's \\ University, Kingston, ON, ${ }^{3}$ Centre \\ for Interprofessional Education, \\ University of Toronto, Toronto, \\ ON, Canada
}

\begin{abstract}
Background: A review of the literature was undertaken by the Canadian Interprofessional Health Leadership Collaborative to investigate the content and competencies of health education programs that teach collaborative leadership and to inform the development of an international collaborative leadership curriculum.
\end{abstract}

Methods: A PubMed and Google Scholar search identified the frequency of key leadership education program terms and was adjusted for six major databases. From the 2,119 references, 250 were selected in a double-blinded manner. A descriptive statistical analysis was performed to determine the patterns, types, learners, models, and competencies addressed. Cross-tabulation and analysis of correlation identified best practices and impacts on learners' knowledge, skills, attitudes/behaviors, and on health system change.

Results: Four types of leadership models were formally identified, ie, traditional leadership, transformational leadership, clinical leadership, and collaborative leadership. The most identified competencies were interprofessional communication, knowledge on how to work in teams and across disciplines, and financial knowledge. The least addressed topics were social accountability and community engagement. Only $6.8 \%$ of the articles reviewed assessed the effectiveness of their program based on patient-centered outcomes and 3.6\% on system change.

Conclusion: This literature review focused on 250 health leadership education programs reported in peer-reviewed journals to address important questions about the competencies, best practices taught, and evaluation of effectiveness of health system change in health leadership educational programs. This review provides information that may encourage the development, implementation, and evaluation of new collaborative leadership programs. The Lancet Commission report in 2010 called for a new breed of collaborative health leader who can work across health professions in community, hospital, and primary care settings. Collaborative leaders must lead change in the face of uncertainty and ambiguity, and must strengthen and build relationships to navigate complex systems. Existing leadership programs do not adequately address the key competencies to prepare future health leaders to rise to these challenges.

Keywords: leadership, health education, collaboration, curriculum, interprofessional relationships, peer review research

\section{Introduction}

Health care systems today are very complex, operating best through constructive interconnections and interrelationships among their many stakeholders. ${ }^{1,2}$ According to the World Health Organization, complex health care systems are not achieving their primary purpose because "health outcomes are unacceptably low across much of the 
developing world, and the persistence of deep inequities in health status is a problem from which no country in the world is exempt". ${ }^{3}$ A health care system includes "all the activities whose primary purpose is to promote, restore or maintain health", and health outcomes might include, for example, "changes in the perceived health status, changes in the distribution of health determinants, or factors which are known to affect the health, well-being and quality of life". 4,5 How can health care systems perform better to achieve valued outcomes? There is growing evidence that, for interdependent organizations with complex tasks, the traditional top-down way of managing and leading change is not the most effective method of leading to influence valued outcomes. ${ }^{6,7}$

To meet the needs of changing complex health care systems, new ways of leading are required. Harnessing the leadership potential of health care professionals through collaborative interrelationships is suggested to be a more effective method for creating new dynamics that share and support complex processes. Establishing collaboration within and across organizations and communities would generate valued sustainable outcomes that are more aligned with, and responsive to, individual and community needs, such as more integrated services. ${ }^{7,8}$

Leading collaboratively to influence complex health care system change requires knowledge, skills, vision, and innovation that transcend single perspectives and discipline boundaries. ${ }^{6,9-11}$ Are health professionals adequately prepared to lead complex health care system change? According to a 2010 workshop entitled "Educating Nurses and Physicians: Toward New Horizons" and the "Lancet Report", there is still little interaction between students and faculty across health disciplines. ${ }^{12,13}$ The requirements necessary to lead health care system change, eg, competencies for effective teamwork and collaboration, are not currently reflected in the curricula and pedagogic models used to teach health professionals. Furthermore, the curricula are not adapted to local contexts. ${ }^{13,14}$ The Lancet Commission recommended fostering leaders as enablers to move seamlessly between health education and health practice. To better prepare health professionals, the Robert Wood Johnson Foundation and the Institute of Medicine identified the need to embed leadershiprelated competencies in the student curriculum and enhance leadership development at practice levels across health care settings. $^{13,15}$

In 2012, the Institute of Medicine Global Forum selected the Canadian Interprofessional Health Leadership Collaborative (CIHLC) as one of four international innovation collaboratives to incubate and pilot ideas for reforming health professional education, as called for in the Lancet Commission report. ${ }^{13}$ The CIHLC is a multi-institutional and interprofessional partnership that includes the faculties and schools of health science, medicine, nursing, public health, rehabilitation, and programs of interprofessional education, representing health care professions at five universities. Led by the University of Toronto, this collaborative consists of the University of British Columbia, the Northern Ontario School of Medicine, Queen's University, and Université Laval as regional leads, as well as their affiliated networks across multiple sites in Canada. The preliminary work of the CIHLC included completion of a scoping review on health leadership. ${ }^{16}$ From this scoping review, it was clear that there is a need to shift away from the individual leader to a collaborative leadership perspective. ${ }^{6}$ Rather than one leader making centralized decisions, the potential of complex health care systems is maximized through shared power and decision-making within the collective. ${ }^{17}$ As stated by Rubin, "collaborative leaders do not necessarily (or only) lead collaboration, they lead collaboratively". ${ }^{18}$

How are current health education programs adequately preparing health students, practitioners, managers, and executives to be effective collaborative leaders? In a recent investigative Canadian survey of educational programs, many prelicensed curricula and continuing education activities address the concept of leadership, but little is known about the type of leadership learned, the learning context, content, activities, and delivery mechanisms. ${ }^{19}$ In addition, evidence regarding the impact of these education activities is not known. To investigate the preparedness of current health education programs to teach the practice of collaborative leadership, a systematic review was completed by the CIHLC. The overall aim of the systematic review was to depict a meaningful portrait of existing leadership programs in the health care sector and to provide data that could inform the development, implementation, and evaluation of new collaborative leadership programs. Specifically, the systematic review addressed three questions: Which competencies/ learning objectives are included in existing health leadership educational models or programs? What are the best practices in terms of learning context, content, activities delivery mechanisms, and evaluation methods? Do existing health leadership programs impact learners' knowledge, skills, attitudes/behaviors, and system change?

\section{Methods}

A preliminary PubMed and Google Scholar search helped to identify and examine the frequency of relevant key leadership 
education program terms. In designing the formal peerreviewed systematic literature search strategy, three key concepts were identified: collaboration, leadership, and education. Key terms and subterms were generated for each concept (eg, collaboration, interdisciplinary, multidisciplinary, interprofessional, multiprofessional, health care team, teamwork, leadership, administrative personnel, mentors, supervision, management and education, curriculum, training, competencies, interprofessional/interpersonal education, professional development, staff development, interprofessional competencies, educational models, faculty development). After testing the search strategy in Medline, it was then adjusted for optimal retrieval in six health databases using keywords, MESH terms, explodables, and/or headings (Medline, Cochrane, EMBASE, PsycINFO-OVID, ERIC, and CINAHL). The entire list of key words used in the search strategy is presented in Table 1. The initial search was conducted between June and August 2012 using the six databases to retrieve all English articles published after January 2000 that contained the keywords associated with the concepts of collaboration, leadership, and education in the abstract. The use of this time frame was based on the assumption that any relevant literature prior to 2000 would be cited in the more recent work.

\section{Double-blinded selection process}

A preliminary selection process was then conducted to verify if keywords related to the three concepts were contained in the article title and/or the abstract. If the keywords were not found in the title and/or the abstract, the paper was excluded. After this initial screening, a double-blinded selection involving two independent research associates was followed to select the papers included in this review. To be included in the analysis, each article had to meet all three selection criteria: an education-based program or intervention with explicit objectives related to leadership and health; a population of learners from prelicensed health programs or from the health sector (practitioners and/or managers); and primary data of interest (impacts at the system level; measurement of knowledge, skills, attitudes and behaviors among learners) and/or secondary data of interest (competencies, content, learning activities, delivery mechanisms, and evaluation methods). To increase interrater reliability and mutual understanding of the selection criteria, the research associates reviewed together and discussed the first $10 \%$ of the screened articles. The double-blinded selection process was conducted as follows. Each research associate read all the titles and abstracts to determine which articles met the selection criteria. For articles that met the selection criteria in both
Table I List of terms used in the literature search according to each concept

\begin{tabular}{|c|c|c|}
\hline \multicolumn{3}{|c|}{ Terms (keyword, MESH terms, explodables, and/or headings) } \\
\hline Collaboration & Leadership & Education \\
\hline Collaborat[?/\$] & Accountability & Communication \\
\hline Cooperative & Administrative & Competency-based \\
\hline behavior & personnel & education \\
\hline “cross & Change & Continuing professional \\
\hline discipline[?,\$]” & management & development \\
\hline "health care team" & $\begin{array}{l}\text { Complex } \\
\text { adaptive systems }\end{array}$ & *curriculum \\
\hline Interdisciplin[?/\$] & Decision-making & Curriculum development \\
\hline $\begin{array}{l}\text { Interdisciplinary } \\
\text { communication }\end{array}$ & $\begin{array}{l}\text { Financial } \\
\text { management }\end{array}$ & Decision-making \\
\hline $\begin{array}{l}\text { "interdisciplinary } \\
\text { health team[?,\$]" }\end{array}$ & *leaders & Education \\
\hline Interprofession[?,\$] & *leadership & Faculty development \\
\hline $\begin{array}{l}\text { Interprofessional } \\
\text { communication }\end{array}$ & $\begin{array}{l}\text { Nursing, } \\
\text { supervisory }\end{array}$ & "Interdisciplinary education" \\
\hline $\begin{array}{l}\text { Interprofessional } \\
\text { relations }\end{array}$ & $\begin{array}{l}\text { Personnel } \\
\text { management }\end{array}$ & $\begin{array}{l}\text { "Interdisciplinary medical } \\
\text { education" }\end{array}$ \\
\hline Interoccupation[?,\$] & $\begin{array}{l}\text { Quality } \\
\text { improvement }\end{array}$ & $\begin{array}{l}\text { "Interprofessional } \\
\text { education" }\end{array}$ \\
\hline "medical care team" & $\begin{array}{l}\text { Quality } \\
\text { management }\end{array}$ & $\begin{array}{l}\text { "Interprofessional } \\
\text { competence" }\end{array}$ \\
\hline multidisciplin[?,\$] & $\begin{array}{l}\text { Social } \\
\text { responsibility }\end{array}$ & "Interprofessional teaching" \\
\hline multiprofession[?\$] & Supervis* & $\begin{array}{l}\text { Inservice training/or staff } \\
\text { development }\end{array}$ \\
\hline multisector & $\begin{array}{l}\text { Total quality } \\
\text { management }\end{array}$ & Mentors \\
\hline Patient care team & & Models, educational \\
\hline Teambuilding & & *professional competence \\
\hline Teamwork & & *professional development \\
\hline Transdisciplin[?,\$] & & *professional role \\
\hline & & Students, health occupations \\
\hline
\end{tabular}

the title and abstract, the percentage of agreement between the two reviewers was $100 \%$. When titles and abstracts did not provide clear information for both research associates, they read the full paper and then decided together, by consensus, whether or not the paper met the selection criteria. When the research associates had a different opinion about a paper, a member of the CIHLC National Steering Committee joined the discussion in order to reach a consensus on whether or not a paper would be selected. The entire selection process, as well as the exact number of papers selected and excluded, is outlined in Figure 1.

\section{Data extraction}

Once the double-blinded selection was completed, each article included was read by one of two research associates. Each research associate extracted data from approximately 


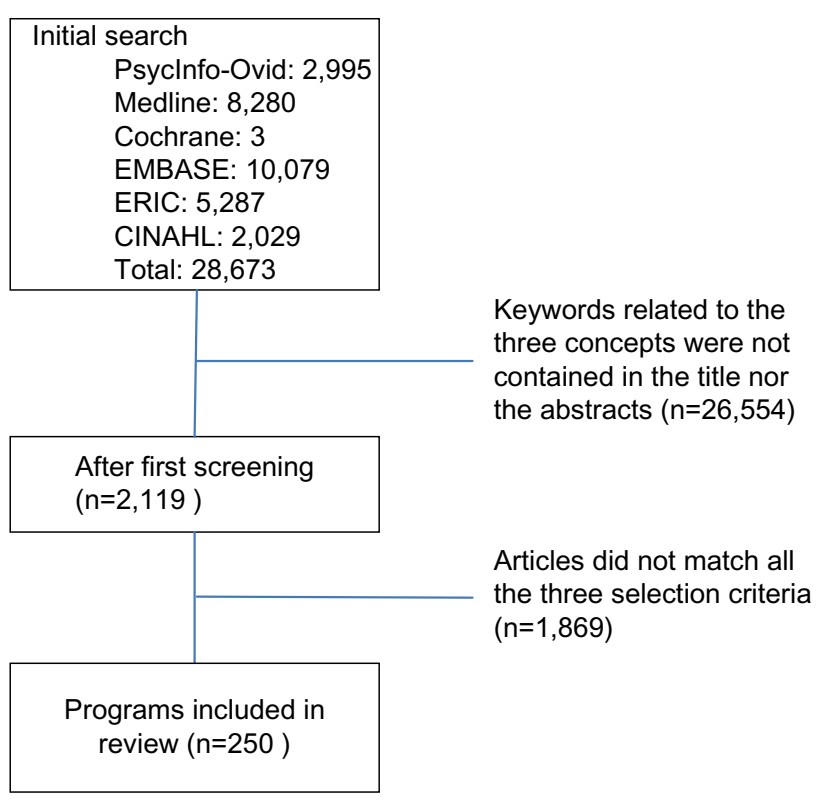

Figure I Selection process.

half of the articles. At the beginning of this process, several discussions were held between the research associates to ensure a common understanding of the data to be extracted. An online data entry form was designed using web-based open-source software called LimeSurvey. The data entry form included 15 sections: reference type, profession stream, learner type, focus of program impacts, outcome level and number, leadership competencies and framework used, location of education, characteristics of program (type, frequency, duration), program delivery format, program assessment method, evaluation framework used, barriers, competencies addressed, level of collaboration, and type of leadership. Determination of the level of collaboration (uniprofessional, multiprofessional, or interprofessional) was based on definitions provided by Barr et al. ${ }^{20}$ Concerning the type of leadership, three categories (traditional leadership, collaborative leadership, transformational leadership) were first determined based on the scoping review conducted by the CIHLC that aims at clarifying the construct definition of collaborative leadership. ${ }^{16}$ For some articles, the type of leadership was identified directly when authors named it specifically. Otherwise, the research associates determined the type of leadership based on the content description provided or by consulting further documentation on the leadership framework or model identified. New categories could also be created if the authors explicitly identified in their paper a type of leadership not included in the initial list. The data extracted from each article were entered into an online data form to constitute the review database.

\section{Data analysis}

The database constituted through the LimeSurvey structured template was uploaded in $\mathrm{IBM}^{\circledR} \mathrm{SPSS}^{\circledR}$ Statistics for Windows version 21.0 software (IBM Corp, Armonk, NY, USA). Descriptive statistical analysis (frequency, mean, standard deviation) was performed to determine the pattern of publication (year and country), types of studies completed, learner audience, types of leadership models reported, and competencies/learning objectives included in the programs. In addition, cross-tabulation and analysis of correlation were performed to identify best practices and impacts on learners' knowledge, skills, attitudes/behaviors, and system change. To measure the degree of relationship between pairs of variables, the Pearson $r$ correlation coefficient was used. These measures were used to further explore correlations between the learning context, content, activities, delivery mechanisms of the leadership programs analyzed, and the learner audience. Pearson coefficient $(r)$ varies in the range of -1 (perfect negative correlation) to +1 (perfect positive correlation). The 0 value represents no correlation (or independence between variables). The higher the coefficient is (in absolute value), the stronger the relationship between analyzed variables, and vice versa. The correlation coefficient and the $P$-value are expressed for each parameter measured. The level of significance was set at $P<0.05$. Finally, the competencies addressed in the analyzed programs, as well as those contained in the main framework used in educational settings, were analyzed and classified into homogeneous subgroups by a hierarchical cluster analysis procedure using Ward's method. ${ }^{21}$

\section{Results}

From the 2,119 references, 250 were selected by the double-blinded process to be included in this review. When interpreting the findings, it is important to keep in mind the limits of this literature review. First, it does not represent all available publications on this topic since only peer-reviewed literature included in health-related and education-related databases was accessed. There are known and likely other existing health leadership education programs that have not been evaluated or presented through scientific articles. Even if a more rigorous method was followed to reduce selection and extraction bias, it is possible that some elements of the programs analyzed were misinterpreted. One had to rely on the description provided in the articles. At times, this information was missing, sometimes incomplete, or unclear. Nevertheless, the findings of this systematic literature review do give a portrait of tendencies in health leadership education programs. 
The majority (73\%) of the selected articles were published between 2007 and 2012 (see Figure 2). Most of the analyzed articles came from the USA (65.6\%), followed by the UK (14.8\%), Canada (6.8\%), and Australia (5.6\%). The largest audience of leadership education and training programs described were managers/executives (33\%), followed by practitioners (21\%), undergraduate students $(15 \%)$, faculty members $(7 \%)$, and postgraduates/residents $(6 \%)$. Four key types of studies were identified, ie, pilot projects, which represented nearly one third (32\%) of references, impact evaluation studies (26\%), program reviews $(21 \%)$, and case studies $(9 \%)$.

\section{Types of leadership}

Four different types of leadership models were formally identified in $40 \%$ of the articles reviewed. They included traditional leadership (20\%), transformational leadership (11.6\%), clinical leadership (4.8\%), and collaborative leadership (3.2\%). A majority of the selected articles (60.4\%) did not specify the type of leadership addressed in the educational program. However, with regards to the leadership frameworks and definitions used, these remaining articles appeared to refer to the traditional concept of leadership. The traditional model is characterized by a top-down approach where an individual leader provides the vision, has strong influence on others, and a strong ability to lead both people as well as processes. ${ }^{5,6}$ The collaborative leadership model is focused on developing leaders that are able to build a shared vision within a group/organization/community and who facilitate the distribution of leadership processes according to the group's expertise, as well as act as a catalyst for shared decision-making processes and collective actions. ${ }^{16}$ When looking specifically to the targeted learners, "traditional leadership" was positively correlated with programs designated for undergraduate $(r=0.316 ; P<0.01)$, postgraduate $(r=0.218 ; P<0.05)$, and practitioner $(r=0.126 ; P<0.05)$ audiences. The only target audience with which "collaborative leadership" was positively correlated was faculty members $(r=0.109 ; P<0.01)$.

Based on the content and description provided in a given article, a total of one to seven competencies/learning objectives were identified for each program (mean 2.8; standard deviation 1.3) that can be regrouped in 20 different topics. Table 2 presents the number of programs that addressed each of the topics identified within this review. Overall, team-level competencies/learning objectives were the most frequently identified in the programs. More precisely, interprofessional communication (37.8\%), knowledge on how to work in teams and across disciplines (33.7\%), and economic and financial knowledge (28.2\%) were the three most addressed topics. The least addressed topics related to social accountability and community engagement principles (eg, developing a common set of values around social accountability; participating in health policy development; addressing priority health concerns of local communities, region, and/or nation; changing local conditions drawing on global resources; and needs of underserved populations). Several correlations between learner types (managers/executives, practitioners, undergraduate students, faculty members, postgraduates/residents) and competencies/learning objectives were significant. The results show that knowledge of the care delivery system, shared problem-solving, and economic and financial aspects

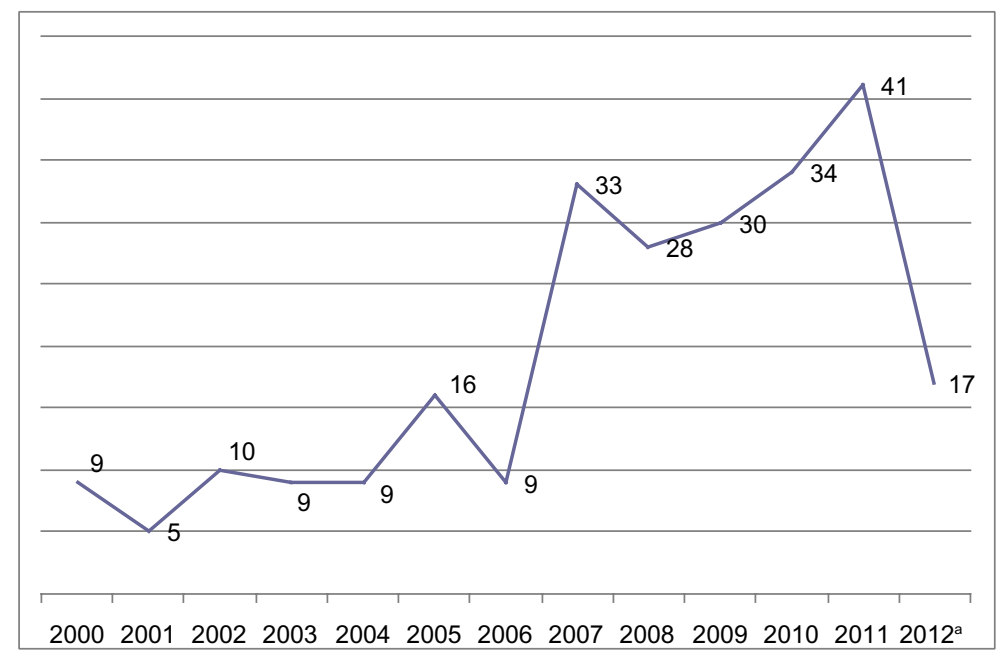

Figure $\mathbf{2}$ Number of articles by publication year. Note: ${ }^{a} 2012$ - publications from January to August. 
Table 2 Number of programs that address each identified topic

\begin{tabular}{|c|c|c|}
\hline \multirow[t]{2}{*}{ Topics $^{\mathrm{a}}$} & \multicolumn{2}{|c|}{ Frequency } \\
\hline & $n$ & $\%$ \\
\hline \multicolumn{3}{|l|}{ Individual level } \\
\hline Power of information technology for learning & 17 & 6.8 \\
\hline Lifelong learning & 24 & 9.6 \\
\hline \multicolumn{3}{|l|}{ Team level } \\
\hline Interprofessional communication & 79 & 31.6 \\
\hline \multicolumn{2}{|l|}{ and across disciplines } & 26.4 \\
\hline Interprofessional conflict resolution & 58 & 23.2 \\
\hline Capacity to develop partnerships & 55 & 22.0 \\
\hline \multicolumn{3}{|l|}{ depending on expertise } \\
\hline Patient/client/family/community centered care & 50 & 20.0 \\
\hline Shared problem-solving & 35 & 14.0 \\
\hline Role clarification & 33 & 13.2 \\
\hline Collaborative leadership & 21 & 8.4 \\
\hline Nonhierarchical relationships in team & 14 & 5.6 \\
\hline \multicolumn{3}{|l|}{ System level } \\
\hline Entrepreneurial development: & 63 & 25.2 \\
\hline economics and finance knowledge & & \\
\hline Evaluation of individual/collective & 52 & 20.8 \\
\hline \multicolumn{3}{|l|}{ performance for quality/safety improvement } \\
\hline Care delivery system & 34 & 13.6 \\
\hline Ethical care & 28 & 11.2 \\
\hline Values around social accountability & 24 & 9.6 \\
\hline Health policy development & 23 & 9.2 \\
\hline $\begin{array}{l}\text { Priority health concerns of local community, } \\
\text { region, and/or nation }\end{array}$ & 21 & 8.4 \\
\hline $\begin{array}{l}\text { Changing local conditions drawing on global } \\
\text { resources }\end{array}$ & 9 & 3.6 \\
\hline Needs of underserved populations & 5 & 2.0 \\
\hline
\end{tabular}

Notes: ${ }^{\text {T}}$ Topics could be designated as learning objectives, content, or competency; ${ }^{\text {b}}$ percentage of 250 analyzed articles.

are commonly present in programs directed at undergraduate students, postgraduates/residents, and practitioners. Although the largest proportion of the leadership programs targeted manager/executive learner audiences, it was noted that the competencies related to collaborative practice concepts were not often addressed for this learner type. Indeed, for the manager/executive learner audiences, the results show negative correlations with "interprofessional conflict resolution" ( $r=-0.169 ; P<0.01)$, "teamwork and collaboration within and across disciplines" $(r=-0.129 ; P<0.05)$, and "role clarification" $(r=-0.108 ; P<0.05)$.

Only $22.8 \%(\mathrm{n}=57)$ of analyzed articles formally identified the leadership framework or model on which the program was based. A total of 41 frameworks were identified. The most used frameworks were the "transformational leadership framework" (used in seven papers), "leadership challenges", Kouzes and Posner (used in four papers), "Kotter's change model" (used in three papers), and "AONE's nurse executive competencies" (used in three papers). By combining all competencies issued from the programs described in the articles, a total of 28 different competencies/learning objectives were retrieved. Each of these competencies/learning objectives was then associated with specific variables (eg, learner type, program duration, delivery format) to identify homogeneous and logical subgroups. Hierarchical cluster analysis resulted in identification of four clusters of competencies addressed in health leadership programs, ie, innovation and quality improvement, tools to support health care transformation, collaborative practice, and personal development.

\section{Learning context}

As shown in Table 3, 65.4\% of the programs reviewed took place in academic settings compared with only $34.6 \%$ in workplace settings. A variety of learning activities were used, such as mentoring, reflective exercises, and project-based learning. Program duration ranged from several hours to one year. Analysis of the professional stream demonstrated that most learner audiences were from nursing $(45.6 \%)$ and, secondly, from medical (26.8\%) profession streams. Based on the description provided by the authors, it was possible to identify the level of collaboration among learners for the programs analyzed. According to Barr et al, uniprofessional education is undertaken by individuals within the same profession, multiprofessional education is when individuals from two or more professions learn alongside one another doing parallel rather than interactive learning, while interprofessional education occurs when individuals engage in learning with, from, and about each other in an interactive way. ${ }^{20}$ The analysis shows that uniprofessional education (68\%) was the most common approach used in the health leadership education programs reviewed. A multiprofessional education approach was used in $22 \%$ of the education programs, while only $10 \%$ used an interprofessional education approach.

The correlations show significant differences in several aspects of the health leadership education programs (Table 4). The delivery format for postgraduate students and residents was positively correlated with both classroom $(r=0.147 ; P<0.01)$ and e-learning $(r=0.116 ; P<0.05)$. The delivery format that correlated positively for postgraduates and residents included facilitated small group/problem-based learning $(r=0.128$; $P<0.01)$, videoconferencing $(r=0.142 ; P<0.01)$, and reflective exercise $(r=0.131 ; P<0.05)$. In contrast, for the programs targeted to practitioners, the location was positively correlated with workshops held in the workplace $(r=0.174 ; P<0.01)$ while the positively correlated delivery formats included lecture/ didactic large group $(r=0.146 ; P<0.01)$ and face-to-face dis- 
Table 3 Characteristics of learning context

\begin{tabular}{|c|c|}
\hline Characteristics & $\begin{array}{l}\text { Percentage of all } \\
\text { articles reviewed }\end{array}$ \\
\hline \multicolumn{2}{|l|}{ Location } \\
\hline Academic settings & 65.4 \\
\hline Workplace settings & 34.6 \\
\hline \multicolumn{2}{|l|}{ Delivery format/learning activities } \\
\hline Lecture/didactic & 27.6 \\
\hline Mentoring & 20.4 \\
\hline Reflective exercises & 18.0 \\
\hline Face-to-face discussion group & 17.6 \\
\hline Simulated cases & 14.0 \\
\hline Coaching & 13.2 \\
\hline Article review/written assessment & 12.8 \\
\hline Workshop & 11.2 \\
\hline e-learning/online discussion group & 10.8 \\
\hline Role playing & 10.0 \\
\hline Clinical projects (individual or group) & 8.0 \\
\hline Community based projects & 8.0 \\
\hline Patient case analysis & 4.0 \\
\hline Shadowing & 3.2 \\
\hline Videoconferencing & 2.4 \\
\hline Patient interaction & 2.0 \\
\hline Blended group (face-to-face and online) & 0.4 \\
\hline \multicolumn{2}{|l|}{ Duration } \\
\hline$>$ One term to $\leq$ I year & 40.0 \\
\hline$>I$ day to $\leq$ I week & 13.6 \\
\hline$\leq \mathrm{I}$ day & 12.8 \\
\hline$>8$ weeks to $\leq$ one term & 11.6 \\
\hline$>$ I week to $\leq 8$ weeks & 9.6 \\
\hline$>$ I year & 7.2 \\
\hline Not specified & 5.2 \\
\hline \multicolumn{2}{|l|}{ Profession stream } \\
\hline Nursing & 45.6 \\
\hline Medicine & 26.8 \\
\hline Dentistry & 4.8 \\
\hline Social work & 4.4 \\
\hline Psychology & 2.4 \\
\hline Pharmacy & 1.6 \\
\hline Pedagogy & 1.6 \\
\hline Occupational therapy & 0.4 \\
\hline Physiotherapy & 0.4 \\
\hline Speech language pathology & 0.4 \\
\hline Audiology & 0.4 \\
\hline Technicians & 0.4 \\
\hline \multicolumn{2}{|l|}{ Level of collaboration among learners } \\
\hline Uniprofessional & 68.0 \\
\hline Multiprofessional & 22.0 \\
\hline Interprofessional & 10.0 \\
\hline
\end{tabular}

cussion group ( $r=0.117 ; P<0.05$ ). The education programs offered to this learner audience primarily used a face-to-face format that supported sharing and discussion of workplace experiences. The only positively correlated delivery format for health leader education programs offered to the managers/ executives learner audience was coaching $(r=0.221 ; P<0.01)$. Finally, correlations also showed that programs identified as specifically addressing collaborative leadership more often adopted a multiprofessional rather than an interprofessional educational approach (the respective coefficients of correlation were 0.194 and $0.186 ; P<0.01)$.

Implementation conditions for education programs were not systematically identified in the analyzed articles; however, some program implementation barriers reported were scheduling $(6 \%)$, difficulty in measurement of outcomes (2.8\%), lack of funding (2.4\%), lack of preparation time (2\%), and lack of preparation on the part of faculty/instructors $(2 \%)$. The administrative barriers most reported were lack of staff support (2.8\%) and lack of financial support (2.4\%).

\section{Leadership education program impact}

Among the analyzed articles, $81.6 \%$ provided information about program impacts and the evaluation process. Among these articles, $39.7 \%$ use a predelivery and postdelivery evaluation instrument and $13.2 \%$ used a longitudinal (from 3 months to 2 years) procedure for data collection. The number of outcome measures used to assess the impact of the leadership education programs varied between one and six (mean 3.07). The frequency of the methods used for the postdelivery assessment is shown in Table 5 .

A majority of these programs measured their impacts based on learner skill changes (56.0\%). This was followed by learner knowledge change $(42.4 \%)$, learner behavior change $(28.0 \%)$, and learner attitude (14.8\%). Only $6.8 \%$ of the articles reviewed assessed the effectiveness of their program based on patient-centered outcomes and 3.6\% on system change. The evaluation methods using postprogram delivery (in descending order of frequency) were attitude/ satisfaction questionnaires (40.4\%), program evaluation feedback (30.4\%), and interview/focus group/debriefing (24.4\%).

The correlations showed that programs designed for practitioners aim to change learner's behaviors $(r=0.121 ; P<0.05)$ and generally measured results at the project/program level rather than at the system level $(r=0.132 ; P<0.05)$. Programs designed for managers/executives are more likely to measure their outcomes at the system level $(r=0.212 ; P<0.01)$, rather than at the individual or program level.

Given the high variability in the competencies addressed and outcomes measured in the leadership education programs, it was not possible to identify any statistically significant correlations that inform the most effective type of leadership education program (traditional leadership versus collaborative leadership). To further explore the impact of health leadership education programs, three categories 
Table 4 Correlation between program characteristics and learning audience (Pearson $r$ coefficients)

\begin{tabular}{|c|c|c|c|c|c|}
\hline \multirow[t]{2}{*}{ Characteristics } & \multicolumn{5}{|l|}{ Learner type } \\
\hline & Undergraduate & Postgraduate & Faculty & Practitioner & Manager/executive \\
\hline Collaborative leadership & - & - & $0.109 * *$ & $-0.137 *$ & $-0.124 *$ \\
\hline Noncollaborative leadership & $0.316 * *$ & $0.218^{*}$ & - & $0.126 *$ & - \\
\hline \multicolumn{6}{|l|}{ Location of education } \\
\hline Classroom & $0.337 * *$ & $0.107 *$ & $0.147 * *$ & $-0.160 * *$ & $-0.212^{* *}$ \\
\hline e-learning & - & - & - & $-0.105^{*}$ & - \\
\hline Community clinic & - & - & - & - & $-0.124 *$ \\
\hline Hospital classroom & - & - & - & $0.119 *$ & - \\
\hline Work e-learning & $-0.136^{*}$ & $0.116 *$ & - & $0.133 *$ & - \\
\hline Workplace & - & $0.15 I^{* *}$ & - & $0.174^{* *}$ & - \\
\hline \multicolumn{6}{|l|}{ Duration } \\
\hline$>2$ days to I week & - & - & - & $0.128 *$ & - \\
\hline One term & $0.232 * *$ & $-0.108 *$ & $0.120 *$ & - & $-0.178 * *$ \\
\hline One year & $-0.140 *$ & - & $0.157^{* *}$ & - & $0.156^{* *}$ \\
\hline \multicolumn{6}{|l|}{ Curriculum delivery format } \\
\hline Lecture/didactic - large group & - & - & $-0.118^{*}$ & $0.146 * *$ & - \\
\hline Face-to-face - discussion group & $0.242 * *$ & $0.122 *$ & - & $0.117 *$ & - \\
\hline Blended group, face-to-face - online & - & - & - & & \\
\hline Facilitated small group/PBL & - & $0.128^{* *}$ & - & - & $-0.18 I^{* *}$ \\
\hline Real cases - patient case analysis & - & - & - & - & $-0.106 *$ \\
\hline Simulated cases & - & - & - & $-0.112 *$ & - \\
\hline Article review/written assignments & $0.135 *$ & - & - & $-0.127^{*}$ & - \\
\hline Videoconferencing & - & $0.142^{* *}$ & - & $0.135^{*}$ & - \\
\hline Coaching & - & - & - & & $0.221^{* *}$ \\
\hline Mentoring & - & - & - & - & $-0.120^{*}$ \\
\hline Community-based projects & $0.279 * *$ & - & - & $-0.118^{*}$ & $-0.101 *$ \\
\hline Reflective exercise & - & $0.131 * *$ & - & - & - \\
\hline \multicolumn{6}{|l|}{ Level of collaboration } \\
\hline Uniprofessional & - & - & $-0.14 I^{*}$ & - & - \\
\hline Multiprofessional & - & - & $0.194 *$ & - & - \\
\hline Interprofessional & - & $0.140 *$ & $0.184 *$ & - & - \\
\hline \multicolumn{6}{|l|}{ Focus of curriculum impact } \\
\hline Learner knowledge & $0.140 *$ & $0.127^{*}$ & - & - & $-0.128 *$ \\
\hline Learner attitude & $0.133^{*}$ & - & $-0.125^{*}$ & - & - \\
\hline Learner behavior/processes & - & - & - & $0.121 *$ & - \\
\hline Learner satisfaction & $-0.147^{*}$ & - & - & - & $0.158 * *$ \\
\hline Patient-centered outcome & - & - & - & - & $0.103 *$ \\
\hline Outcomes measured at program level & - & - & - & $0.132 *$ & - \\
\hline Outcomes measured at system level & - & - & - & - & $0.212 * *$ \\
\hline \multicolumn{6}{|l|}{ Post delivery assessment methods } \\
\hline Knowledge test & $0.315^{* *}$ & - & - & - & $-0.185^{* *}$ \\
\hline Self-assessment & $-0.127 *$ & $-0.122 *$ & - & - & - \\
\hline Reflection journaling & - & $0.130 *$ & - & $-0.106 *$ & - \\
\hline Program evaluation feedback & - & - & $-0.131 *$ & 0.150 ** & - \\
\hline Peer or 360 degree assessment & $-0.106 *$ & - & - & - & $0.120 *$ \\
\hline Observation eg, skills & - & - & - & $-0.137^{*}$ & $0.116^{*}$ \\
\hline Presentation & $0.143 * *$ & - & - & - & $-0.116 *$ \\
\hline Interview/focus group/debrief & - & $0.103^{* *}$ & - & - & $0.120^{*}$ \\
\hline \multicolumn{6}{|l|}{ Competence analysis alignment } \\
\hline Towards health and social needs & - & - & - & $0.140 *$ & - \\
\hline $\begin{array}{l}\text { Engage other health professionals } \\
\text { appropriate to the specific care situation }\end{array}$ & - & $0.161^{* *}$ & - & $0.124 *$ & - \\
\hline Economics and finance knowledge & $0.224 * *$ & $0.205^{* *}$ & - & $0.206 * *$ & - \\
\hline Interprofessional conflict resolution & $0.130 * *$ & - & - & $0.193^{* *}$ & $-0.169 * *$ \\
\hline Knowledge of values and ethical care & - & - & - & $0.252^{* *}$ & - \\
\hline $\begin{array}{l}\text { Knowledge on how to work in team and } \\
\text { collaborate within and across discipline }\end{array}$ & - & - & - & $0.122 *$ & $-0.129 *$ \\
\hline
\end{tabular}


Table 4 (Continued)

\begin{tabular}{llllll}
\hline Characteristics & Learner type & & & & \\
\cline { 2 - 6 } & Undergraduate & Postgraduate & Faculty & Practitioner & Manager/executive \\
\hline Knowledge on care delivery system & $0.335^{*}$ & $0.272^{*}$ & - & $0.190^{* *}$ & - \\
Lifelong learning & - & $0.135^{*}$ & $0.110^{*}$ & $0.225^{* *}$ & $-0.139^{*}$ \\
Participating in health policy development & $-0.128^{*}$ & - & - & $0.127^{*}$ & - \\
Patient/client/family/community centered & $0.338^{* *}$ & - & - & $0.164^{* *}$ & - \\
Promote a new professionalism & $-0.118^{*}$ & - & - & $0.177^{* *}$ & - \\
Role classification & - & - & - & $0.20 I^{* *}$ & $-0.108^{*}$ \\
Shared problem solving & - & $0.109^{*}$ & - & $0.17 I^{* *}$ & - \\
To be able to rapidly change local & - & $0.130^{*}$ & - & - & - \\
conditions drawing on global resources & & & & & \\
\hline
\end{tabular}

Notes: -, not statistically significant; $* P<0.05 ; * * P<0.01$.

Abbreviation: PBL, problem-based learning.

of learner were distinguished based on similar learning experiences and needs: prelicensed students/postgraduates/ residents who constitute the next generation for the health care system; practitioners who are the people working in the health care system; and managers/executives, who are leading/managing the health care system. Correlations were then determined for each category. The focus of the leadership programs for postgraduate students and residents was on knowledge improvement $(r=0.127 ; P<0.05)$. Positive outcomes for this category of learners were measured at the individual level $(r=0.192 ; P<0.01)$. The programs targeted at practitioners focused primarily on changes in behaviors and processes $(r=0.121 ; P<0.05)$. Positive outcomes for this category were mostly measured at the project/program level $(r=0.132 ; P<0.01)$. Health leadership education programs offered to managers/executives evaluated their impact mainly based on learner satisfaction $(r=0.158 ; P<0.01)$ and on patient-centered outcomes $(r=0.103 ; P<0.05)$. However, positive outcomes were also

Table 5 Program postdelivery assessment methods

\begin{tabular}{ll}
\hline Assessment methods & $\begin{array}{l}\text { Percentage of all } \\
\text { articles reviewed }\end{array}$ \\
\hline Satisfaction questionnaires & 40.4 \\
Program evaluation feedback & 30.4 \\
Interview/focus group/debrief & 24.4 \\
Self-assessment on leadership development & 19.2 \\
Peer or 360 degree assessment & 10.0 \\
Quality improvement project evaluation & 9.6 \\
Observation of skills and behaviors & 9.2 \\
Knowledge test & 6.0 \\
Reflection/journaling & 5.6 \\
Presentation & 4.4 \\
Other (class participation, stakeholder satisfaction, & 6.4 \\
number of educational innovations, educational & \\
portfolio preparation) & \\
Not specified & 16.8 \\
\hline
\end{tabular}

measured at the system level for this category of learners $(r=0.212 ; P<0.01)$.

\section{Discussion}

This literature review focused on 250 health leadership education programs reported in peer-reviewed journals from 2000 to 2012 and specifically addressed the following questions: Which competencies/learning objectives are included in existing health leadership educational programs? What are the best practices in terms of learning context, content, activities, and delivery mechanisms? Do existing health leadership programs impact learners' knowledge, skills, attitudes/behaviors, and system change? Given the high variability of the programs analyzed in this review, the few programs that clearly identified the type of leadership addressed, and the limited scope of evaluation used, it is not possible to identify definitive evidence regarding these questions. Nevertheless, the findings provide a meaningful picture of existing leadership programs in the health care sector and give information that may encourage the development, implementation, and evaluation of new collaborative leadership programs.

Types of leadership are not systematically identified in most of the articles reviewed, but the results show that the majority of reviewed educational programs relates to traditional leadership. The emphasis on traditional leadership suggests that collaborative leadership is a relatively new concept in the health education field. However, the latter approach is necessary for long-term transformational system change to occur. ${ }^{22,23}$ It is interesting to note that, in 21 programs, collaborative leadership was identified as a specific competency/learning objective, while only seven of these programs provided explicit information that described and/or defined this type of leadership. Regarding the content of the existing leadership programs, the analysis shows that all competencies and learning objectives could be regrouped in four categories: innovation and quality improvement; tools 
to support health care transformation; collaborative practice; and personal development. Further exploration of specific competencies/learning objectives addressed in the programs highlights that the most addressed topics could be associated at the team level. These findings support the hypothesis that existing educational programs aim at developing leaders who "lead collaboration" rather than developing leaders who "lead collaboratively" as suggested by Rubin. ${ }^{18}$ Moreover, many authors argue that collaborative leadership should be anchored in social accountability and community engagement in order to foster sustainable changes in the health care sector. ${ }^{24}$ The results from this literature review show that very few leadership programs addressed these topics.

The results of this literature review indicate high variability in the delivery formats available in health leadership programs, and demonstrate that the delivery format used is strongly related to the target learner audience. There was no strong evidence to conclude that a particular duration is linked with impact on learners' knowledge, skills, attitudes/ behaviors, and system change. The findings show that a mix of delivery formats, including traditional education activities and new technologies, were used in the leadership programs offered to prelicensed students, postgraduates, and residents. For the manager/executive learner audience, coaching was an effective method for improving the capacity to provide better support for their employees, colleagues, and partners in achieving their common goals and objectives. Overall, a blended-learning model that combined both face-to-face activities and e-learning delivery formats was the most popular delivery format. Using a blended format combined with coaching, facilitator support, and experiential small group/team work has been shown to be effective ${ }^{25,26}$ because it further assists in identifying the key challenges facing a project, organization(s), and/or community, and planning short-term and longer-term strategies with stakeholders to achieve valued health care outcomes.

Of the 250 programs analyzed, most used a uniprofessional or multiprofessional education approach instead of an interprofessional approach and were directed at the professions of medicine and nursing. This situation is not aligned with the principles of collaborative leadership, where diversity in the expertise and opinions of individuals is highly valued. ${ }^{6}$ This diversity is reflected in the interprofessional education approach that teaches learners to take collective actions through a sharing of power as they learn about, from, and with each other. The findings could suggest that the interprofessional education approach is not yet recognized, understood, or widely used in the leadership field.
This situation may reflect challenges related to designing and/or implementing interprofessional educational activities where the learners will truly learn about, from, and with each other regarding collaborative leadership. Alternatively, the limited use of the interprofessional approach may reflect an emphasis on the traditional leadership model. Based on these findings, the design of health leadership programs that address the needs of individuals from different disciplines within and across different organizational settings, as well as needs that bridge education and practice settings, is preferred. This also reflects the recommendation in the Lancet Commission report to "promote interprofessional and transprofessional education that breaks down professional silos while enhancing collaborative and nonhierarchical relationships in effective teams". ${ }^{13}$

\section{Conclusion}

These findings provide a meaningful portrait of current trends in leadership education for health professionals that could be useful to inform the development, implementation, and evaluation of new collaborative leadership programs. To adequately prepare health students, practitioners, managers, and executives to be effective collaborative leaders in order to support processes that generate outcomes of maximum value for the collective, several program development recommendations are presented below. Competencies related to traditional leadership styles are well developed in existing health care leadership educational programs, but this is not the same for collaborative leadership. Given that only $3.2 \%$ of programs analyzed addressed competencies related to this type of leadership, current and future collaborative leadership programs must be developed in order to meet the complex needs of the health care system. Concerning the learner audience, the category of managers/executives appears to be less targeted by current programs that include competencies related to collaborative leadership. However, an effort has to be made to include this leadership style in the programs and to better define concepts, competencies, subcomponents, and learning outcomes related to collaborative leadership. Development of a clear competency framework will both contribute to the conceptualization of collaborative leadership and help education organizations to position their unique contributions within the existing offer of leadership programs. When developing a collaborative leadership program, it is important to clearly identify the target learner audience and evaluate its collaborative leadership education needs in order to choose the most suitable and effective delivery format. To incorporate the concept of 
collaborative leadership in practice, the learning methodology ideally mirrors the concept of collaborative leadership, ie, collaborative learning methodology. Moreover, using an interprofessional education approach appears to be the most aligned with the principles of collaborative leadership. This approach suggests a need to develop learning activities that give a group of learners from different disciplines the opportunity to truly learn about, from, and with each other. Despite the fact that the programs reviewed showed high variability in their delivery formats, the blended learning format, combining face-to-face instruction with computer-mediated and online instructions, is the most appropriate for maximizing knowledge acquisition and accessibility of a collaborative leadership program. Moreover, learning activities that promote participants working together, such as service-learning or action-learning projects, could help future collaborative leaders to benefit from peer coaching and mentoring. They would then be well supported to better face organizational or community health care challenges.

Finally, developing a high quality leadership program that has significant valued health care system outcomes requires a robust evaluation plan that includes ongoing monitoring to support adaptation to new contexts. This evaluation plan needs to be based on an evaluation framework that includes indicators that measure both short-term and long-term impacts on learners and health care system level changes. These indicators must be able to capture significant changes in health care reforms and enable innovation in order to tackle complex health challenges.

As one of four international innovation collaboratives of the Institute of Medicine's Global Forum on Health Professions Reform, the CIHLC is leading the development, implementation, and evaluation of a global collaborative leadership program that builds upon the Lancet Commission's recommendations for health education reform. ${ }^{13}$ The CIHLC is focusing on collaborative leadership as a critical enabler of patient-centered and familycentered care. This review will inform the development of this international program for leaders to bring unique skills, experiences, and perspectives together and, when combined with community engagement and social accountability, should contribute effectively to improved health outcomes. Collaborative leadership can help health care providers and organizations to transition from provider-focused thinking to patient-focused and family-focused collaboration by engaging all relevant stakeholders in the process of health care delivery and decision-making, including patients and their families. The CIHLC's vision is "collaborative leadership for health system change" to globally transform education and health. Realizing this vision will require building upon existing global initiatives to enable faculty and learners to become collaborative leaders, ultimately improving health outcomes and health human resources through innovation in research and education.

\section{Acknowledgments}

The CIHLC project is a consortium of five partner Canadian universities (University of British Columbia, University of Toronto, the Northern School of Medicine, Queen's University, and Université Laval), and is funded by the Ministry of Health and Long Term Care and by individual contributions of the partner universities. For full membership of the CIHLC National Steering Committee, please see our website (http:// cihlc.ca/about-us/national-steering-committee/). The authors would like to take this opportunity to thank a number of people for making this research possible. Firstly, thanks to Paola Durando, librarian, Bracken Library, Queen's University, who supported us on a number of aspects of our literature research. Secondly, thanks to Mathew Gertler, Jelena Kundacina, Jane Seltzer, Benita Tam, and Deanna Wu for supporting this project in various ways during their work in the CIHLC Secretariat. Thirdly, we thank the other members of the National Steering Committee for their support during this research, both in terms of their invaluable expertise and their moral support, namely, Lesley Bainbridge, Sue Berry, Marion Briggs, Serge Dumont, Maura MacPhee, and David Marsh. For more information on the CIHLC project, please visit our website (http://cihlc.ca).

\section{Disclosure}

The authors report no conflicts of interest in this work.

\section{References}

1. Rouse WB. Health care as a complex adaptive system: implications for design and management. Bridge. 2008;38(1):17-25.

2. Begun JW, Zimmerman B, Dooley K. Health care organizations as complex adaptive systems. In: Mick SM, Wyttenbach M, editors. Advances in Health Care Organization Theory. San Francisco, CA, USA: JosseyBass; 2003.

3. http://www.who.int/en/ [homepage on the Internet]. Strengthening health systems to improve health outcomes: WHO's framework for action. Geneva, Switzerland: World Health Organization; 2007. Available from: http://www.who.int/healthsystems/strategy/everybodys_business.pdf. Accessed November 25, 2013.

4. http://www.who.int/en/ [homepage on the Internet]. The World Health Report 2000 - Health systems: improving performance. Geneva, Switzerland: World Health Organization; 2000. Available from: http://www. who.int/whr/2000/en/whr00_en.pdf. Accessed November 25, 2013.

5. http://www.who.int/en/ [homepage on the Internet]. Health Impact Assessment. Geneva, Switzerland: World Health Organization. Available from: http://www.who.int/hia/about/glos/en/index1.html. Accessed January 5, 2014. 
6. Browning HW, Torain DJ, Patterson TE. Collaborative health care leadership: a six-part model for adapting and thriving during a time of transformative change. Greensboro, NC, USA: Center for Creative Leadership; 2011. Available from: http://www.ccl.org/leadership/ pdf/research/CollaborativeHealth careLeadership.pdf. Accessed November 25, 2013

7. Edgren L, Barnard K. Complex adaptive systems for management of integrated care. Leadersh Health Serv. 2012;25(1):39-51.

8. Chreim S, Williams BE, Coller KE. Radical change in health care organization: mapping transition between templates, enabling factors, and implementation processes. J Health Organ Manag. 2012;26(2): 215-236.

9. Denis J-L, Lamothe L, Langley A. The dynamics of collective leadership and strategic change in pluralistic organizations. Acad Manage J. 2001;33(4):809-837.

10. Dickson G, Briscoe D, Fenwick S, MacLeod Z, Romilly L. The PanCanadian Health Leadership Capability Framework Project: a collaborative research initiative to develop a leadership capability framework for health care in Canada. Ottawa, ON, Canada: Canadian Health Services Research Foundation; 2007. Available from: http://www.cfhi-fcass. ca/Migrated/PDF/Health_Leadership_Framework_E.pdf. Accessed February 13, 2014.

11. Norman CD, Buchan A, Best A, Mortimer S, Huerta T. Evaluating the science of discovery in complex health systems. American Journal of Evaluation. 2011;32(1):70-84.

12. Josiah Macy Jr. Foundation and Carnegie Foundation for the Advancement of Teaching. Educating nurses and physicians: toward new horizons advancing inter-professional education in academic health centers. New York, NY, USA: Josiah Macy Jr. Foundation; 2010. Available from: http://www.macyfoundation.org/docs/macy_pubs/JMF_Carnegie_ Summary_WebVersion_(3).pdf. Accessed February 13, 2014.

13. Frenk J, Chen L, Bhutta ZA, et al. Health professionals for a new century: transforming education to strengthen health systems in an interdependent world. Lancet. 2010;376(9756):1923-1958.

14. Josiah Macy Jr. Foundation. Transforming patient care: aligning interprofessional education with clinical practice redesign: conference recommendations; 2013. Available from: http://macyfoundation. org/docs/macy_pubs/TransformingPatientCare_ConferenceRec.pdf. Accessed November 25, 2013.

15. http://www.iom.edu/ [homepage on the Internet]. The future of nursing: leading change, advancing health. Washington, DC, USA: The National Academies Press; 2011. Available from: http://www.iom.edu/ /media/ Files/Report\%20Files/2010/The-Future-of-Nursing/Future\%20of $\% 20$ Nursing\%202010\%20Recommendations.pdf. Accessed November 25, 2013.
16. Creede C. What Informs the Topic of Collaborative Leadership for Health Care System Change? (Report on Scoping Review). Toronto, ON, Canada: Canadian Interprofessional Health Leadership Collaborative; 2012.

17. Abel AL, Roi R, Nair S, Lannquist Y. Strategic leadership development: global trends and approaches. Ottawa, ON, Canada: The Conference Board of Canada; 2013. Available from: https://www.med.mun.ca/ getdoc/58a756d2-1442-42ed-915b-9295b6d315c6/Curran--ResarchSynthesis-Paper.aspx. Accessed February 13, 2014.

18. Rubin H. Collaborative Leadership: Developing Effective Partnerships for Communities and Schools. 2nd ed. Thousand Oaks, CA, USA: Corwin; 2009.

19. Gertler M. Methodologies and Findings of the Inventory Review of Select Canadian Leadership Courses Available to Health Professionals. (Report on Curriculum Inventory). Toronto, ON, Canada: Canadian Interprofessional Health Leadership Collaborative; 2013.

20. Barr H, Koppel I, Reeves S, Hammick M, Freeth D. Effective Interprofessional Education: Assumption, Argument and Evidence. London, UK: Blackwell; 2005.

21. Ward JH Jr. Hierarchical grouping to optimize an objective function. J Am Stat Assoc. 1963;(58):236-244.

22. Best A, Greenhalgh T, Lewis S, Saul JE, Carroll S, Bitz J. Largesystem transformation in health care: a realist review. Milbank $Q$. 2012;90(3):421-456.

23. Chreim S, Williams B, Janz L, Dastmalchian A. Change agency in a primary health care context. Health Care Manage Rev. 2010;35(2): 187-199.

24. Marsh D, Paterson M, Berry S. Transforming health systems through collaborative leadership: making change happen! Paper presented at the 5th International Symposium on Service-Learning. Stellenbosch University, Stellenbosch, South Africa, November 20-22, 2013.

25. Curran V. Interprofessional Education for Collaborative Patient-Centred Practice. Ottawa, ON, Canada: Health Canada; 2004. Available from: http://research.library.mun.ca/154/1/Interprofessional_Education_for_ collaborative_patient_centred_practice.pdf. Accessed November 25, 2013.

26. D'amour D, Oandasan I. Interprofessionality as the field of interprofessional practice and interprofessional education: an emerging concept. J Interprof Care. 2005;19(Suppl 1):8-20.
Journal of Healthcare Leadership

\section{Publish your work in this journal}

The Journal of Healthcare Leadership is an international, peer-reviewed, open access journal focusing on leadership for the health profession. The journal is committed to the rapid publication of research focusing on but not limited to: Healthcare policy and law; Theoretical and practical aspects healthcare delivery; Interactions between healthcare and society and evidence-based practices;

\section{Dovepress}

Interdisciplinary decision-making; Philosophical and ethical issues; Hazard management; Research and opinion for health leadership; Leadership assessment. The manuscript management system is completely online and includes a very quick and fair peer-review system. Visit http://www.dovepress.com/ testimonials.php to read real quotes from published authors. 